\title{
THE RENAL CIRCULATION IN SHOCK ${ }^{1}$
}

\author{
BY HENRY D. LAUSON, STANLEY E. BRADLEY,2 AND ANDRE COURNAND, wITH \\ THE TECHNICAL ASSISTANCE OF VERA VESSEY ANDREWS
}

\author{
(From the Departments of Physiology and Medicine, New York University College of Medicine; the \\ Department of Medicine, College of Physicians and Surgeons, Columbia University; the Third \\ Medical Division and the Tuberculosis Service of Bellevue Hospital, New York City)
}

(Received for publication January 22, 1944)

The status of the circulation through the kidneys during peripheral circulatory failure, or shock, is of interest inasmuch as kidney function is entirely dependent upon the circulation, and because a knowledge of the alterations in circulatory dynamics in one highly vascular region, such as the kidney, may contribute to the understanding of the mechanisms of regional redistribution of the circulation in the shock syndrome.

Clinical material. These studies formed an integral part of an investigation of shock in man, carried out at Bellevue Hospital. Methods of study and organizational detail have been previously reported (1). As far as possible, the procedures were planned to yield a comprehensive, well-integrated picture.

Renal clearances were measured in 35 patients, 18 to 71 years of age, of whom 27 were males and 8 were females. ${ }^{8}$ They may be classified etiologically as follows: (a) skeletal trauma without shock, 3 cases; with shock, 11 cases; (b) hemorrhage without shock, one case; with shock, 9 cases (including 3 patients with cirrhosis of the liver and ruptured esophageal varices, and 3 who were later found to have mild or moderate essential hypertension); (c) peritoneal inflammation, 2 cases; one with necrosis of the lower colon and peritonitis resulting from a Lysol enema, but not in shock; and one in severe collapse from a strangulated hernia of 4 days' duration; $(d)$ third degree burns, 2 cases; one in moderate shock and the other showing no evidence of

1 This investigation was carried on under a contract, recommended by the Committee on Medical Research, between the Office of Scientific Research and Development and Columbia University, with the collaboration of New York University; Dr. Dickinson W. Richards, Jr., responsible investigator, and Dr. Homer W. Smith, collaborating investigator.

Now associated with the Department of Medicine, Boston University School of Medicine.

Includes all patients studied up to March 1, 1943. shock; (e) head injury, 7 cases, all of whom were in coma and died shortly after study. Patients in group (e) were not in shock and stand in sharp contrast to the others. In 7 cases, complete studies were repeated 11 to 76 days after the episode of circulatory failure.

\section{METHODS}

The rate of glomerular filtration was measured by the clearance of either mannitol or inulin (both were used in a few cases) and the effective renal plasma flow was calculated from the clearance of sodium p-aminohippurate, except in a few instances where diodrast was used." The plan of study was modelled after that of Smith, Goldring, and Chasis (5), but was freely modified according to the exigencies of each situation, which, from the nature of the investigation, were numerous. Analytical methods used are described in detail by Goldring and Chasis (6).

4 Mannitol (25 per cent) and sodium p-aminohippurate (20 per cent) in ampoules were supplied through the courtesy of Sharpe and Dohme, Inc., and inulin (10 per cent) through the courtesy of the Warner Institute for Medical Research.

Dosage varied, but the following quantities were most of ten used: Priming: mannitol, $80 \mathrm{cc}$; inulin, 20 to $30 \mathrm{cc}$.; p-aminohippurate, 9 to $13 \mathrm{cc}$. of 1.68 per cent solution. Infusion: mannitol, 3 to 4 per cent; inulin, 0.4 to 0.6 per cent, and p-aminohippurate, 0.2 to 0.24 per cent, where the rate of infusion was $4 \mathrm{cc}$. per minute. The infusion was made up in physiological saline obtained from the Sterisol Ampoule Company.

The clearance of p-aminohippurate has been found to be identical with that of diodrast in dogs (2) and in man (3). The identity of the clearance of inulin and mannitol in the normal human subject has been established (4). Simultaneous clearances performed in 4 cases of moderate or severe shock and 1 case of head injury (normal filtration rate and high urine flow in the last-mentioned) yielded an average mannitol/inulin ratio of about 0.90 . Since our analytical method for inulin differed from that previously used in this laboratory, and since, at the time of comparisons, minor technical difficulties were experienced with the inulin method, it appears likely that the average difference of 10 per cent represents a systematic technical error rather than a true difference in clearance. For practical purposes, the clearances of mannitol and inulin in cases of shock are considered identical. 


\section{TECHNICAL SOURCES OF ERROR}

Brief comment on some of the variables encountered will aid in proper evaluation of the data. The renal study was but one of several procedures carried out as nearly simultaneously as possible. Since all cases were emergencies, most of the planning had to be done rapidly. Cooperation varied greatly, being good with apathetic patients in severe shock and of ten poor with alcoholics. Washout of the bladder was sometimes made difficult by tensing of abdominal muscles or pain from adjacent injury. In the more severe cases, it was not always possible to carry out the renal study before starting blood transfusion, hence the results are sometimes complicated by the effect of treatment. Initial anuria occasionally made it necessary to postpone the study until after partial recovery. In order to obtain sufficient urine for analysis, collection periods were of ten longer than 15 minutes, although they seldom exceeded 30 minutes. Rapid changes in clearances might thus have been obscured. Because of the difficulty in predicting clearances, constant plasma concentrations were seldom obtained, but more frequent blood sampling minimized error caused by fluctuating levels. On the whole, it is believed that technical errors have been few and relatively small in magnitude. No case has been excluded from the data presented in this report.

\section{RESULTS}

Clinical data and results of the studies are summarized in Table I. Columns 9, 10, and 11 show the approximate values for cardiac output per minute per square meter of body surface (cardiac index), mean arterial pressure, and whole blood volume per square meter of body surface, all estimated to the midpoint of the renal study. 5 These are close approximations

5 This was done in one of two ways: If there had been no therapy prior to the renal study, and if the patient's condition was apparently stabilized, the actual hemodynamic measurements made before the kidney work

Summary of renal clearance studies. Unless alcoholism was considered to dominate the clinical picture, its presence is not mentioned under etiology. Regarding treatment preceding the renal study, only significant therapy is noted, all patients having received varying quantities of physiological saline incidental to maintaining the patency of the intra-auricular catheter. The degree of shock existing when the group's studies were begun was evaluated as follows: 0 , no shock; + , mild to moderate shock; ++ , severe shock. For details of classification, reference is made to the previous report (1). By the time of the renal study, there was significant improvement in the condition of a number of the patients as a result of treatment, but because of the difficulty of estimating this improvement, only the original degree of shock is indicated.

In the majority of instances, 3 successive periods or less were measured. These have been averaged without regard only (except blood pressures), but are useful in interpreting the results of the clearance studies. The remaining columns of Table I present the clearance data and derived values corrected to 1.73 square meters of body surface. It should be emphasized that all values derived from the hippurate or diodrast clearances are understood to be qualified by the term "effective," as defined by Smith, Goldring, and Chasis (5). Effective whole blood flow was derived in the usual manner from the hippurate clearance and the hematocrit.

Columns 18 and 19 show two derived values which have proved useful in the study of renal hemodynamics. The effective renal vascular resistance is an over-all term derived from the mean arterial pressure and effective renal blood flow, and is defined as the loss of hydrostatic pressure between the renal artery and renal vein per unit of renal blood flow. It is ex-

(usually within the hour) were taken. If the conditions were changing, spontaneously or as a result of therapy, observations before and after the clearance study were utilized for the estimate.

- This concept derives from the law of Poiseuille, and may be applied to this situation as an approximation. If total resistance in the renal vessels is defined in terms of the loss of pressure from the renal artery to the renal vein (equivalent to loss of potential energy derived from the cardiac systole) and the blood flow through the kidneys, the only errors in the calculation will be those resulting from inadequate measurement of the terms of the equation itself, which is

$$
R_{K}=\frac{\text { mean arterial pressure-renal vein pressure }}{\text { renal blood flow }} .
$$

Mean pressure in the femoral artery is probably a good measure of the renal arterial mean pressure. Renal venous

to period-to-period variation, which was occasionally quite large. Where a study was repeated the results are presented separately. In 2 cases, G. J. and A. S., 7 and 6 successive periods, respectively, showed practically no variation, hence are presented as single averages. In 3 other cases, J. S., T. D., and M. M. (5, 9, and 7 consecutive periods), there were considerable changes, both in clearances and general hemodynamics, necessitating some arbitrary judgment in averaging periods for Table $I$ and Figures 1 to 7 . However, all periods are shown in the charts illustrating these cases (Figures 8 to 12).

The adrenal cortex extract, 50 Cartland-Nelson units per cc., was supplied through the courtesy of the Upjohn Company.

Sources from which the normal values for the hemodynamic and renal measurements were taken are given in the legends to Figures 1 to 7. 


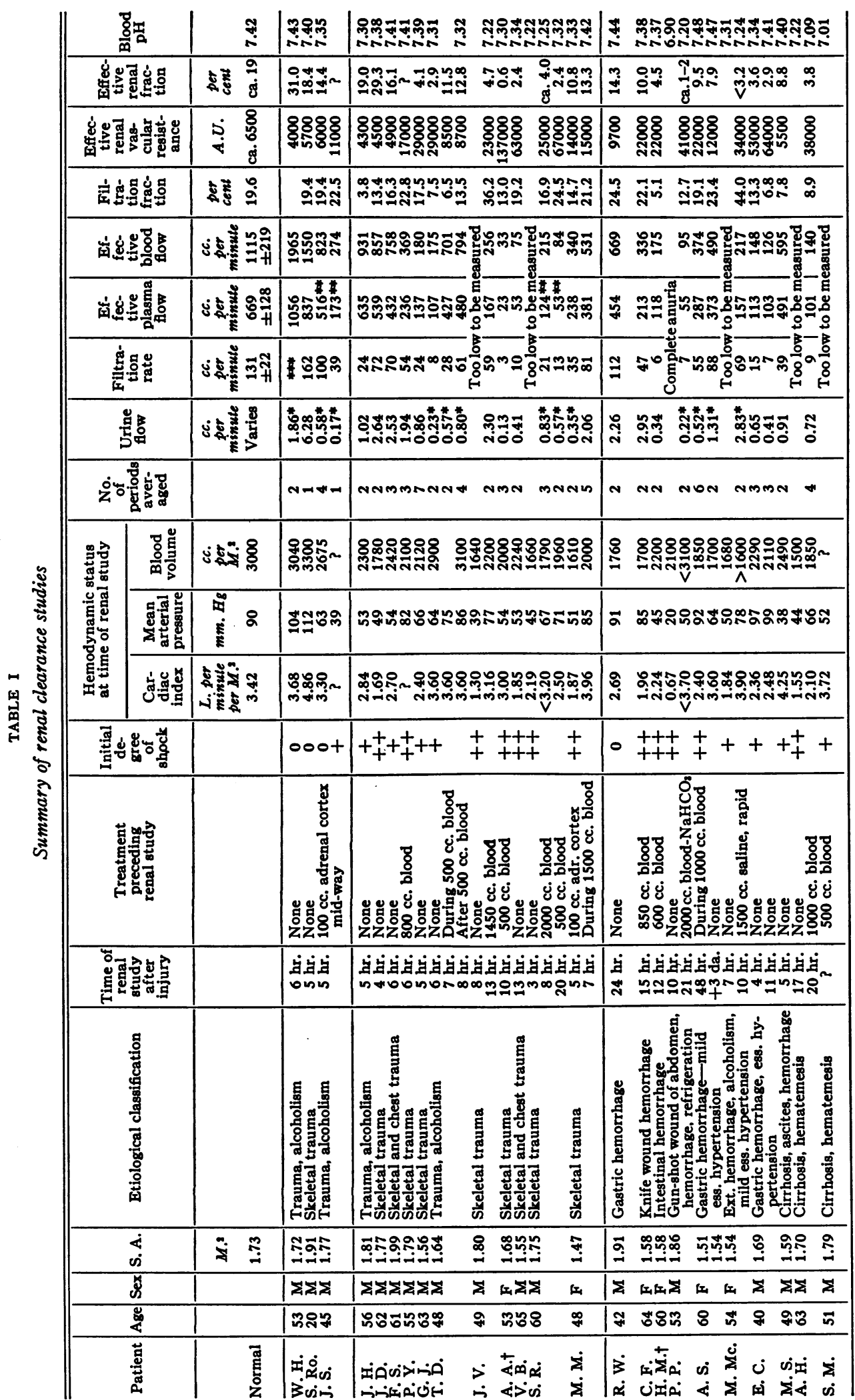




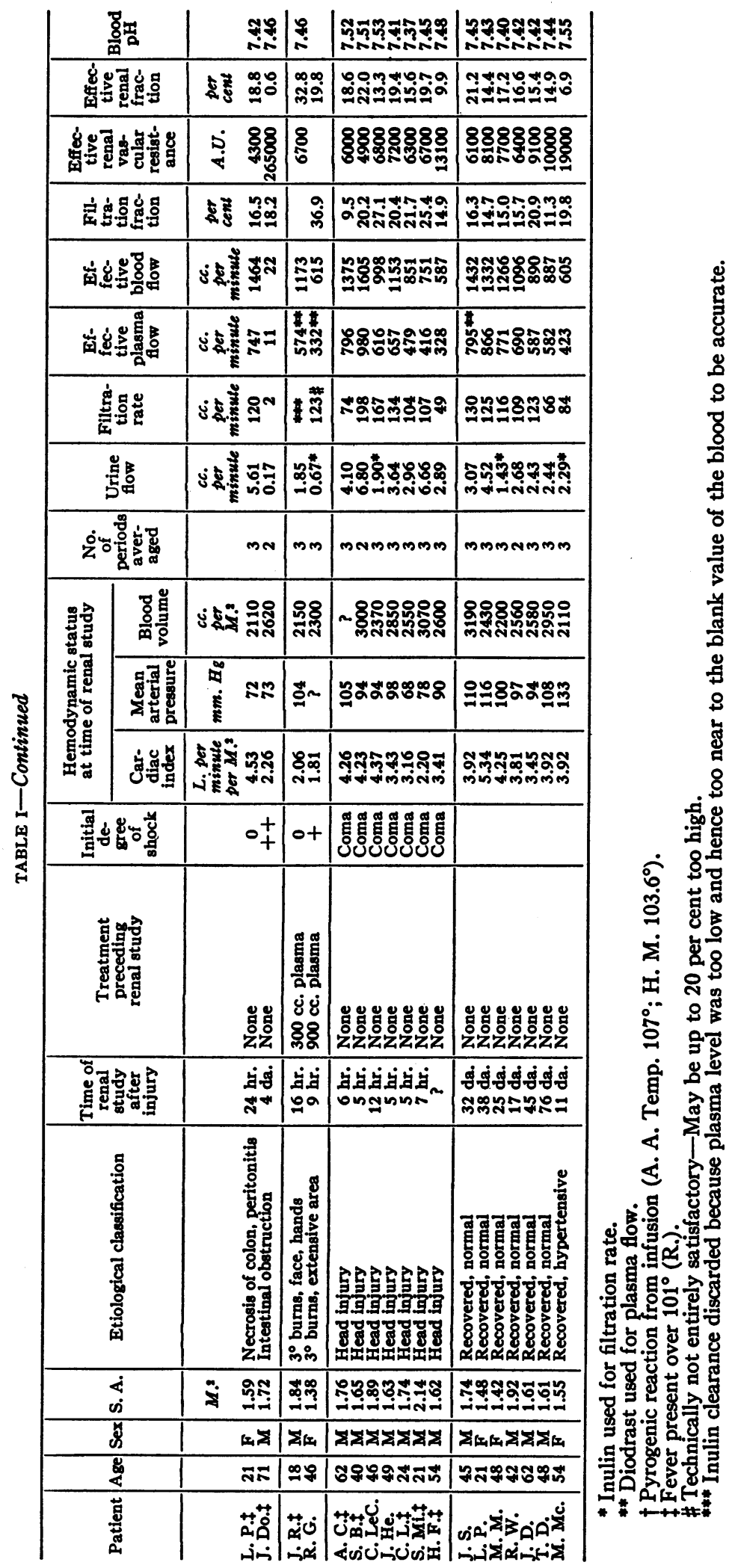




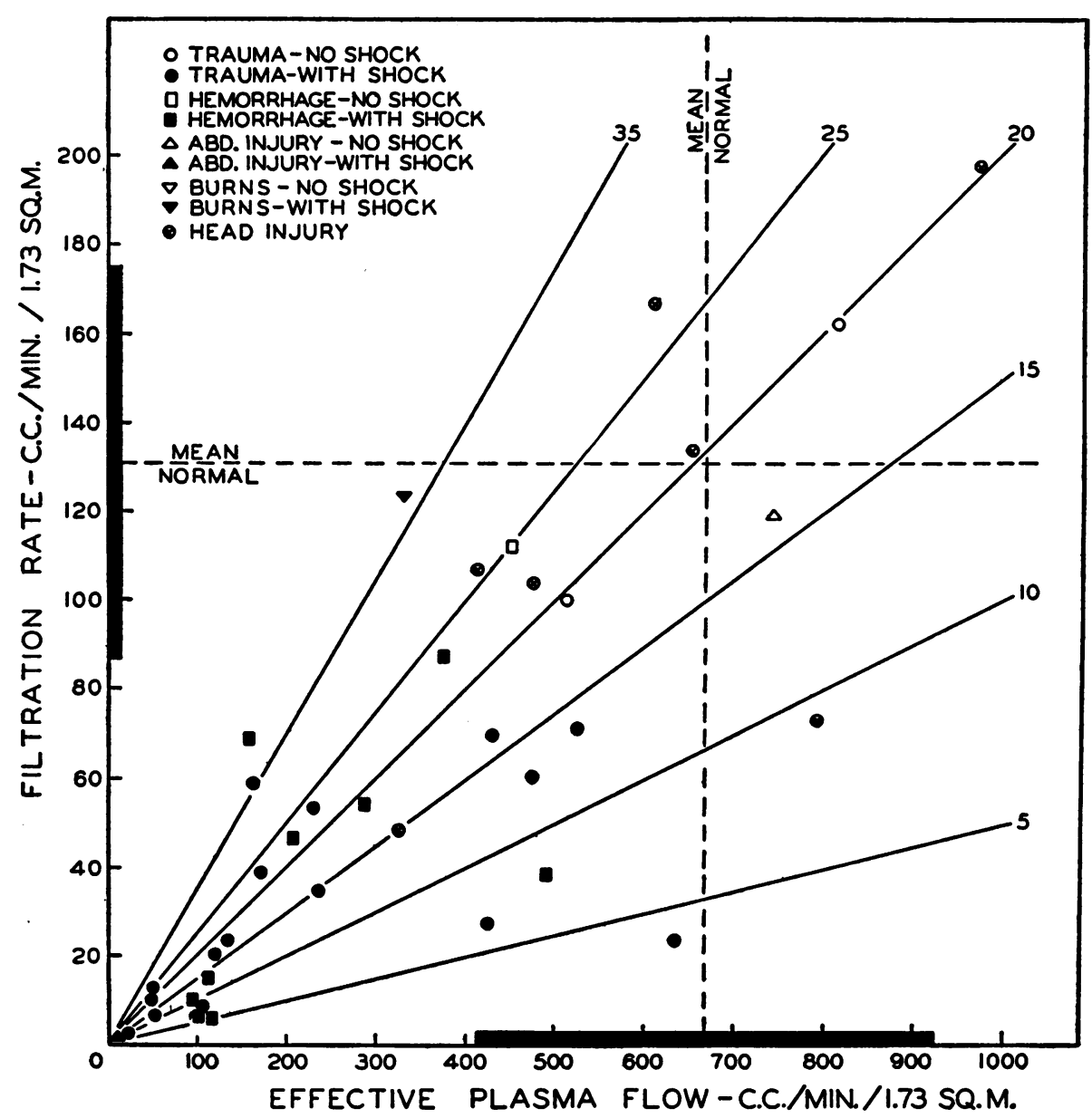

Fig. 1. Showing Relationship Between Filtration Rate and Renal Plasma flow

In this and succeeding charts, each point represents the average of several clearance periods, and all cases given in Table I are shown. The solid columns on the ordinate and abscissa represent \pm two times the standard deviations for normal males and females, taken from Goldring, Chasis, Ranges, and Smith (8). The diagonal lines define 5 per cent intervals of filtration fraction. E.g., all points along the line, "20," represent a filtration fraction of 20 per cent. Note that the majority of values from patients in shock (solid symbols) fall below the normal ranges of both filtration rate and plasma flow. The tendency toward high filtration fractions, in spite of pyrexia, in the head injury cases is clearly shown.

pressed in absolute units as dynes $\mathrm{cm} .^{-5}$ second. Renal fraction expresses the proportion of the

pressure is certainly small in comparison to $P_{m}$, but since it has not been measured in intact man, the term has arbitrarily been set equal to zero. The third factor, renal blood flow, derives from the plasma clearance of hippurate or diodrast and is subject to the same limitations as the clearance itself. In practice, the mean pressure is converted to dynes per $\mathrm{cm} .^{2}$ by the factor of 1332 , the blood flow is expressed in cc. per second, and the result given in absolute units.

It will be noted that the definition does not indicate how or where the hydrostatic energy is dissipated, but only how much. Whether in a given case the greatest resistance total cardiac output which perfuses the functional renal tissue, and is given by the ratio:

renal fraction

$$
=\frac{\text { renal blood flow (cc. per minute) } \times 100}{\text { cardiac output (cc. per minute) }} .
$$

is afferent or efferent to the glomerulus is not given by our calculation. Lamport (7) has derived equations which attempt to determine this distribution, but we are not yet prepared to apply them to our data. However, the overall resistance value seems more useful for examining the altered relationship between the renal and systemic circulations in shock. 


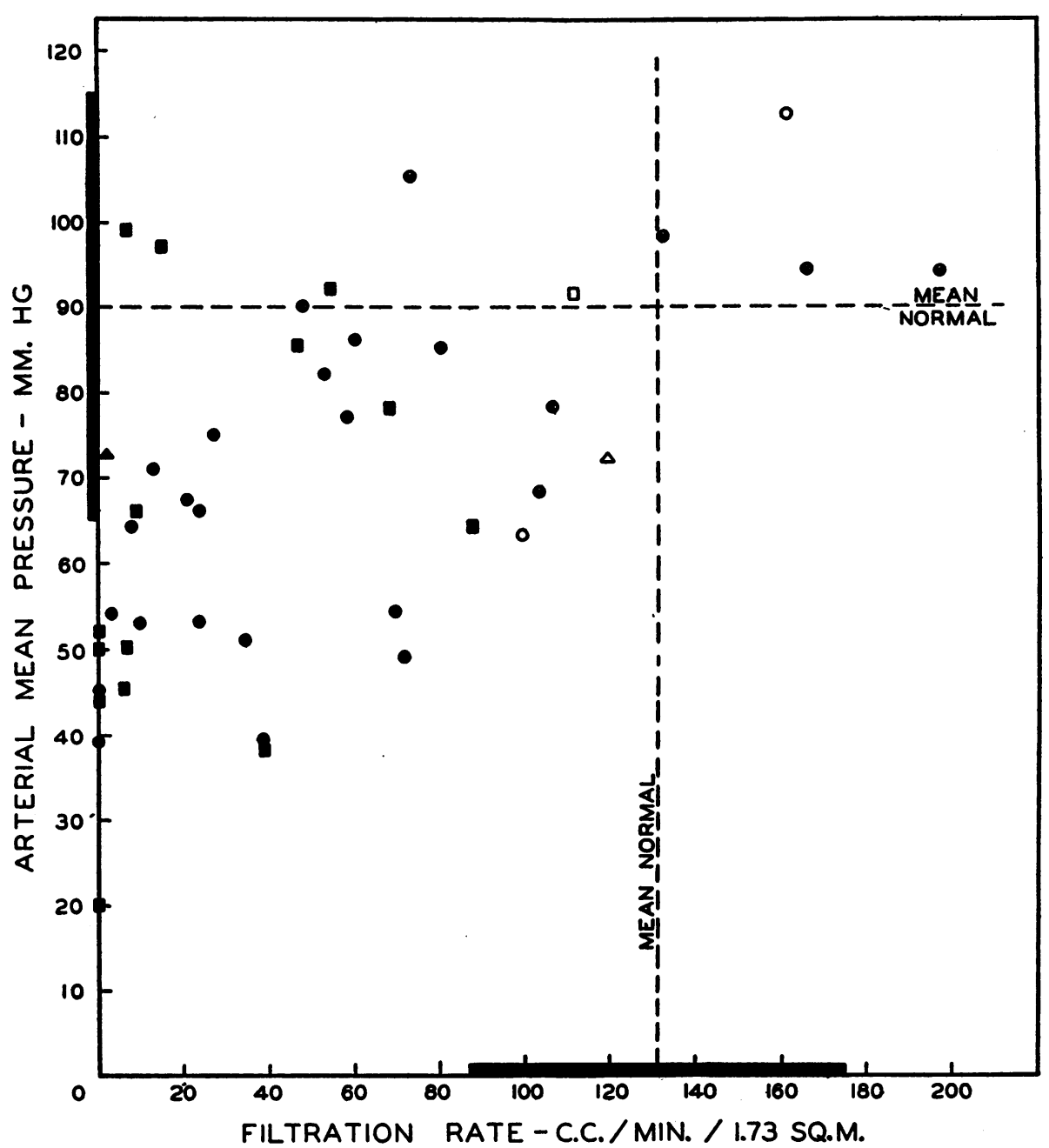

Fig. 2. Relationship Between Mean Arterial Blood Pressure and Rate of Glomerular Filtration

The normal range for the latter is the same as in Figure 1. Mean arterial pressure was obtained by planimetric integration of femoral pressure pulse tracings recorded by means of a Hamilton type manometer (9). The normal range for mean pressure was modified from data of Bradley and Smith (10). Note that in most shock cases, the decrease in filtration rate is greater than the corresponding fall in arterial mean pressure.

A decrease in the renal fraction, simultaneous with a decrease in total cardiac output, indicates that functional tissue in the kidneys is receiving less than its normal proportion of the blood flow; and conversely, that other areas outside the kidney, or non-functioning tissue in the kidney, must be receiving more than the usual proportion. In other words, change in this value indicates the shunting of blood to or away from the functional renal tissue relative to the normal condition. The effective renal vascular resistance is chiefly of value in determining whether a reduction in renal blood flow is the result solely of decreased arterial pressure or whether additional factors are present.

The major results of this study may be summarized in the statement that the rate of glomerular filtration and effective renal plasma flow are significantly reduced in nearly every patient suffering from shock, the degree of reduction being roughly proportional to the severity of shock. The data of Table I are 
shown graphically in Figures 1 to 7, which are presented to illustrate the chief alterations in renal vascular dynamics.

1. Filtration rate, plasma flow, and filtration fraction. The values for filtration rate and plasma flow range from a high normal level in patients who suffered injury or hemorrhage but who were not in shock, down to practically zero in the most severely shocked patients. The scatter of data may be seen in Figure 1, in which filtration rate is plotted against plasma flow. All the data from patients not in shock lie within the normal range. In the head injury group, the clearances were normal, or slightly above or below the normal range. The diagonal lines define intervals of filtration fraction. The

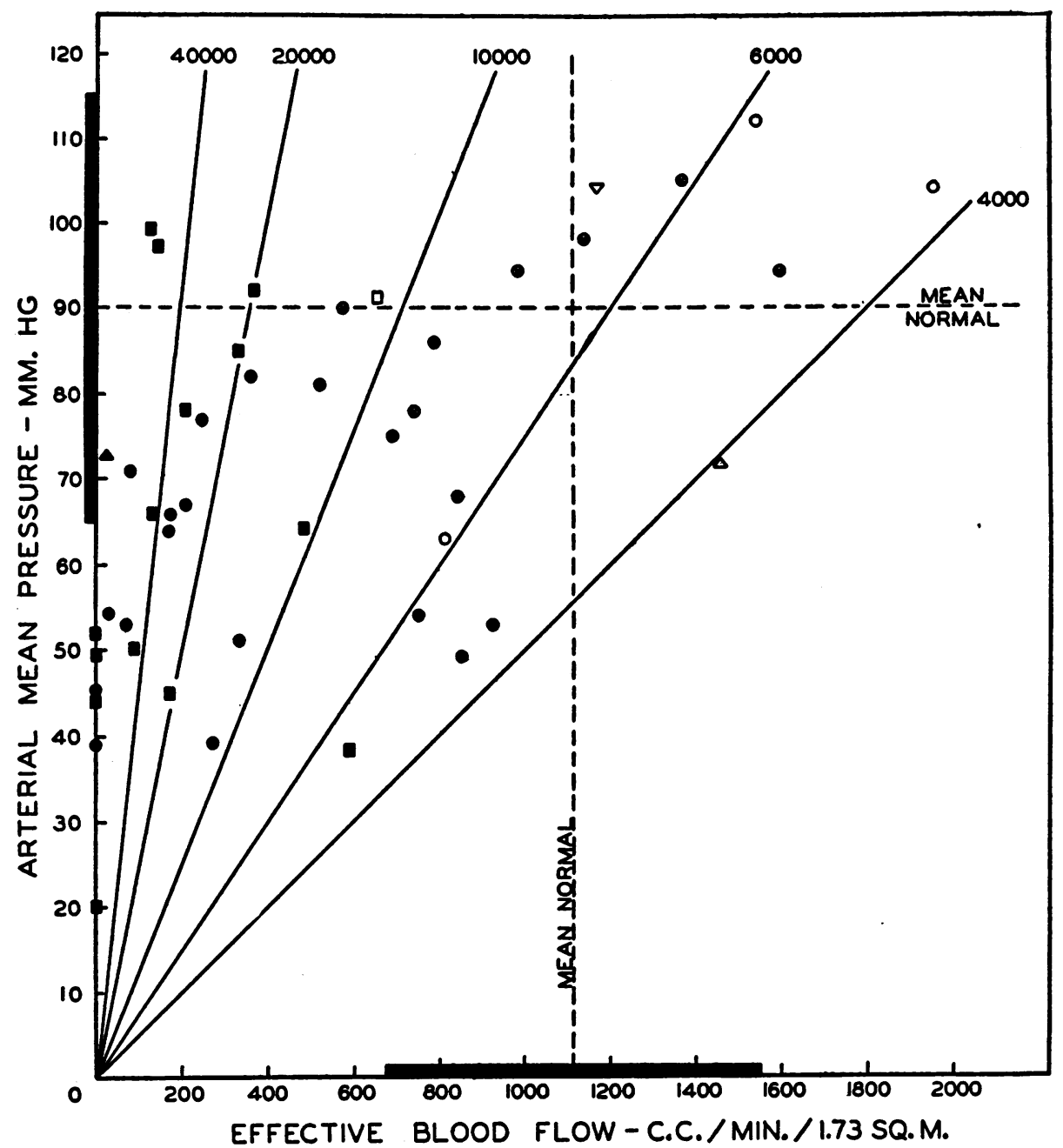

Fig. 3. Relationship Between Arterial Mean Pressure and Renal Blood Flow

The normal range for the latter was taken from Goldring, Chasis, Ranges, and Smith (8). The diagonal lines originating from zero indicate successive values, expressed in absolute units, for effective renal vascular resistance. Thus, all points along a given line have the same value for resistance, the magnitude of which expresses the ratio

$$
R_{\mathrm{K}}=\frac{P_{m}}{\text { R.B.F. }}, \text { converted to absolute units. }
$$

The normal range is approximately 4000 to $10,000 \mathrm{~A}$. U. Note that in most shock cases, the points lie in zones of increased resistance, indicating that vasoconstriction occurred in the kidneys. See text for details. 


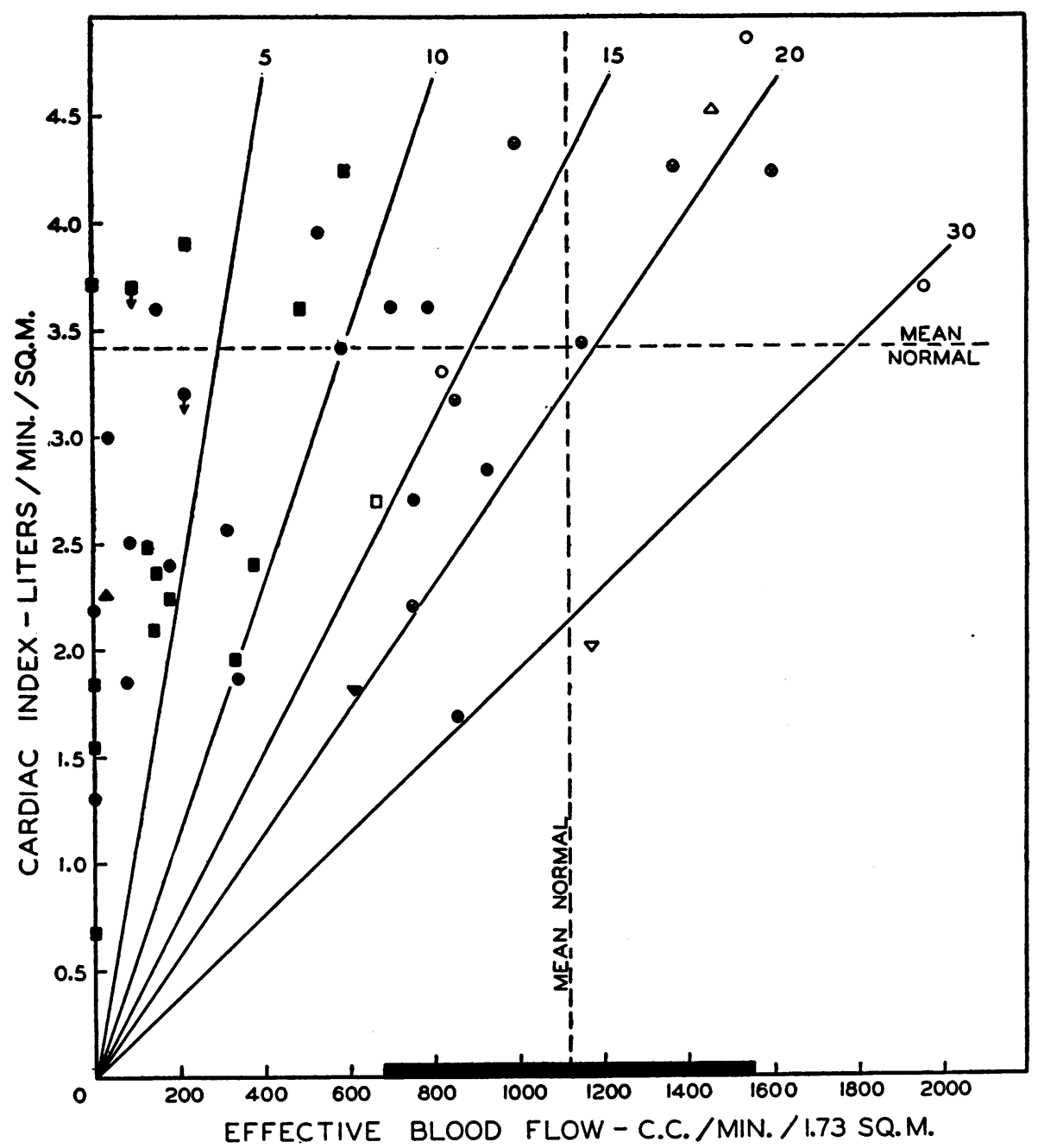

Fig. 4. Relationship Between Cardiac Output in Liters per Minute per Square Meter of Body Surface and the Renal Blood Flow in Cc. per 1.73 Square Meters

Cardiac output was measured by the Fick method, for details of which see Cournand $e t$ al. (1). The diagonal lines originating from zero indicate successive values of the renal fraction, expressed as per cent, calculated on the basis of the "ideal" surface area of 1.73 square meters. This arbitrary choice was necessary since the renal fraction expresses the ratio of 'renal blood flow to the total cardiac output rather than to cardiac output per square meter of surface area. For surface areas larger or smaller than 1.73 square meters, the corresponding renal fraction lines would lie closely adjacent to the lines shown in this chart. Hence, the latter are mathematically accurate only for the surface area of 1.73 square meters, and are intended solely as approximate guides for the evaluation of the relationship between cardiac output and renal blood flow.

In the normal recumbent man, about 15 to 25 per cent of the cardiac output flows through the kidneys. It is seen that in most shock cases, the renal fraction was considerably less than normal, indicating that as the cardiac output decreased, blood was shunted away from the kidneys. The two points with inverted arrows represent clearances obtained fairly long after the last cardiac output determination, and it is likely that by the time of the renal study, the cardiac output had decreased somewhat. 


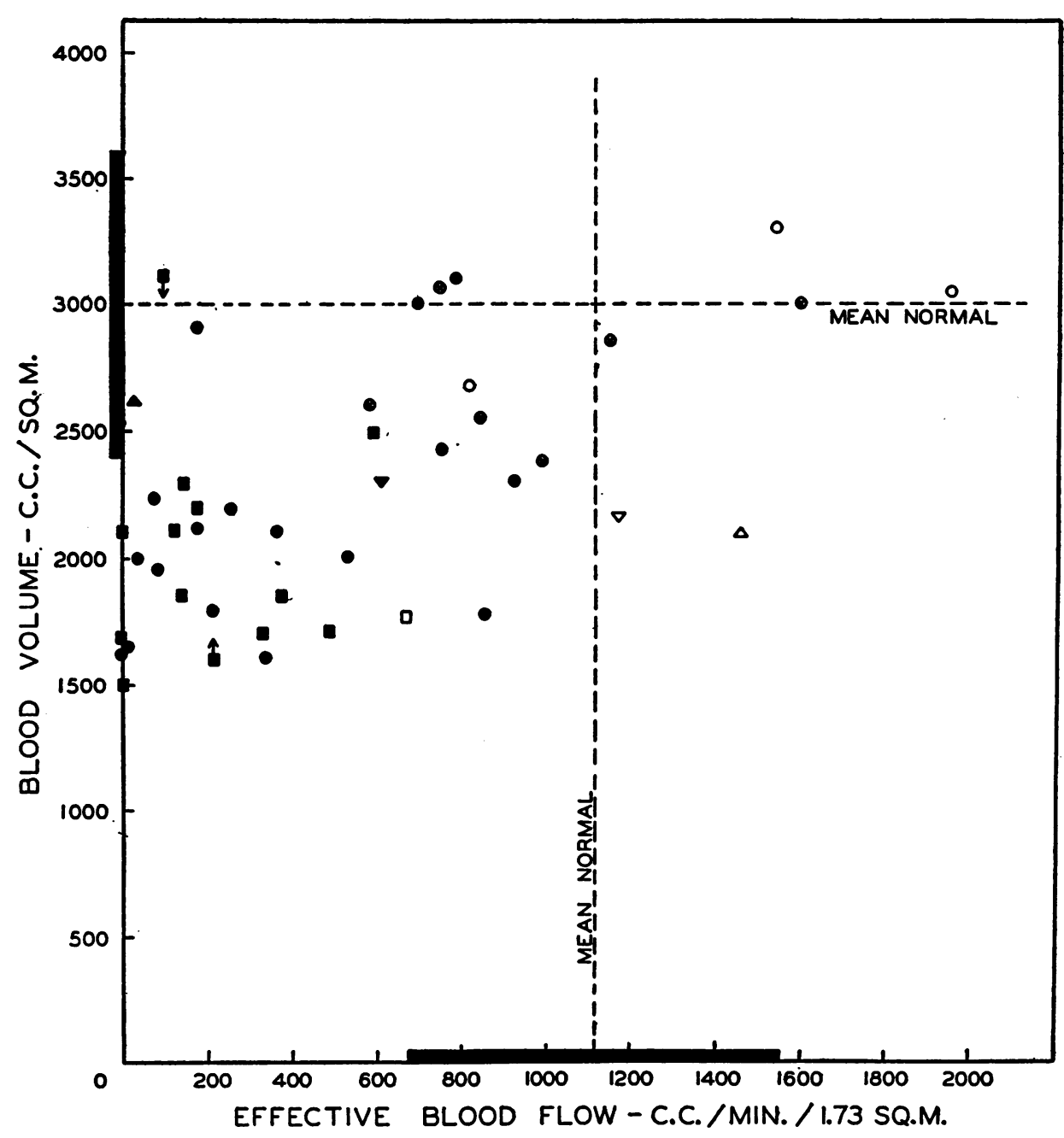

Fig. 5. Correlation Between Blood Volume in Cc. per Square Meter of Body Surface and the Renal Blood Flow

The normal range of blood volume is an approximation based on data gathered from the literature and from their own experience by Drs. M. I. Gregersen and R. P. Noble. Blood volume was determined by the dye method of Gregersen, for details of which see Cournand et al. (1).

The correlation is improved somewhat by the deletion of the three points in the upper left of the chart. In P. P. (indicated by the inverted arrow), the last blood volume measurement was made more than 3 hours before the clearance study, and since the patient's blood pressure and general condition had deteriorated during that time, it is probable that further blood loss had occurred. Case J. Do., represented by the solid triangle, had suffered from strangulated hernia for $\mathbf{4}$ days, making it likely that the toxic and infectious factors contributed to his collapse in addition to loss of body water. Furthermore, it is probable that the hippurate clearance underestimates the true renal blood flow if there has been prolonged renal anoxia which could reduce the extraction ratio. The third symbol represents the initial value of $T$. $D$. in whom severe acute alcoholism was believed to have caused marked fall in blood pressure in spite of a cardiac output and blood volume near normal (see Figure 10). 


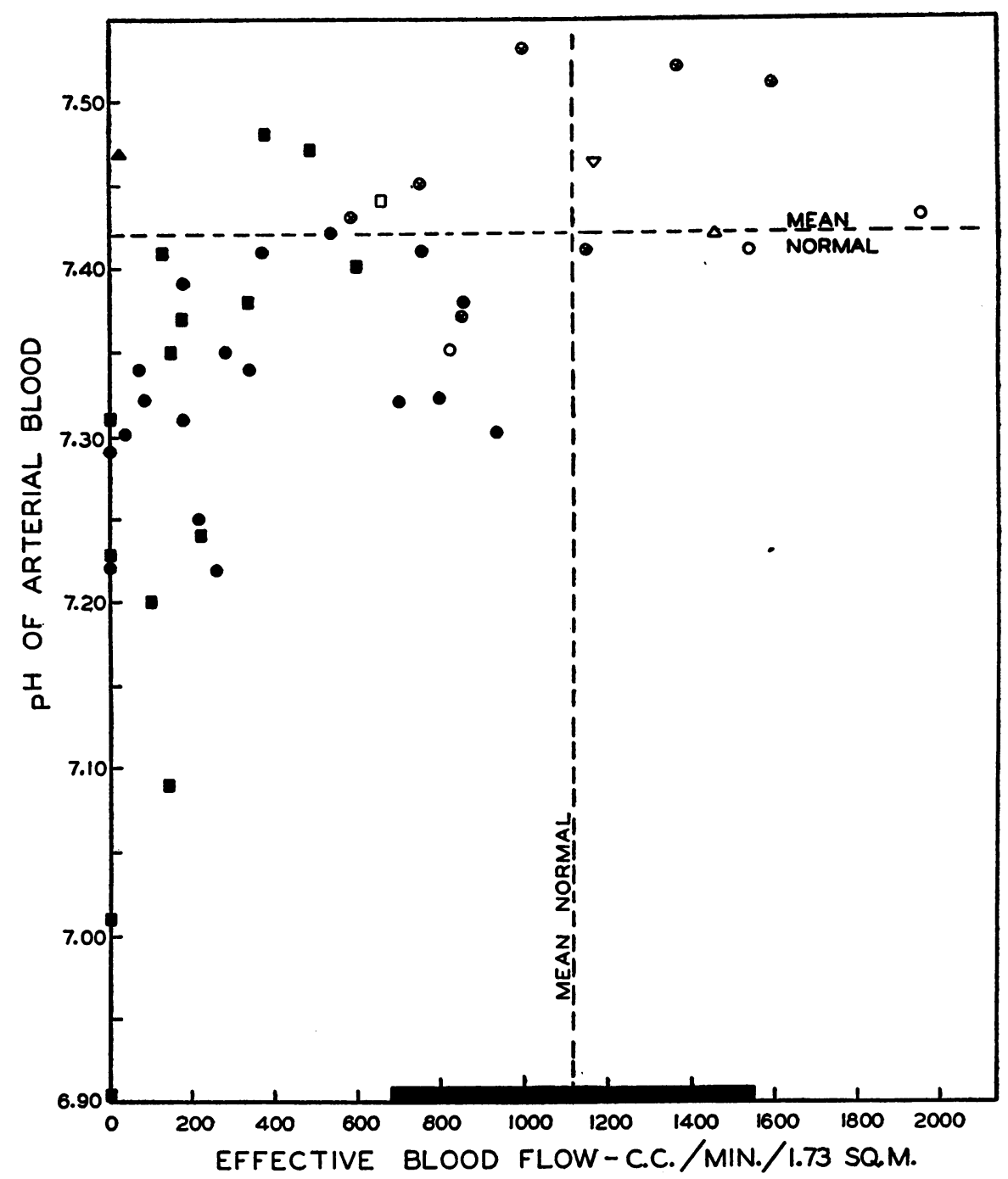

Fig. 6. Relationship Between the pH of Arterial Blood and the Renal Blood Flow

See Cournand et al. (1) for method of measurement of $\mathrm{pH}$. Note that some extremely low blood flows were associated with normal blood $\mathrm{pH}$, a fact which precludes the possibility that acidosis is the primary cause of renal ischemia in shock. See discussion in text.

individual points tend to be grouped almost equally above and below the average normal filtration fraction of about 20 per cent.

Table II is an analysis of the data shown in Figure 1, in terms of several variables encountered in the study. The range of 15 to 25 per cent approximately defines the normal limits of filtration fraction. The tendency toward higher filtration fractions is clearly seen in 5 of the 7 head injury cases, a fact worthy of emphasis, since the degree of fever seen in most of these cases would ordinarily be associated with a reduced filtration fraction. The 4 patients classified as not being in shock fall in the normal range, whereas the filtration fraction was below normal in 13 of the shock cases and above normal in 2.

2. Filtration rate related to arterial blood pressure. Figure 2 shows in general that the rate of filtration decreased with fall in mean arterial pressure, a result that would be anticipated from the fact that the glomerulus functions as a passive filter. In most cases, however, the filtration rate fell far more than could be ac- 
TABLE II

Analysis of Figure 1

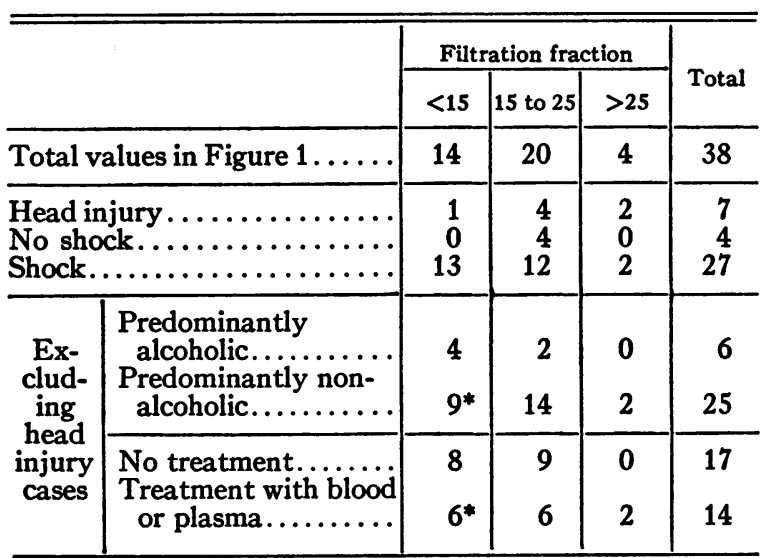

Excludes all values from Table I which are designated as "too low to be measured." W. H. and J. R. not shown because filtration rate is lacking. Also excluded is M. Mc. because treatment differed from the others.

* Two of these patients suffered severe chills and fever at the time of renal study (A. A. and H. M.). Hence it is conceivable that their filtration fractions might have been higher in the absence of pyrogenic reactions.

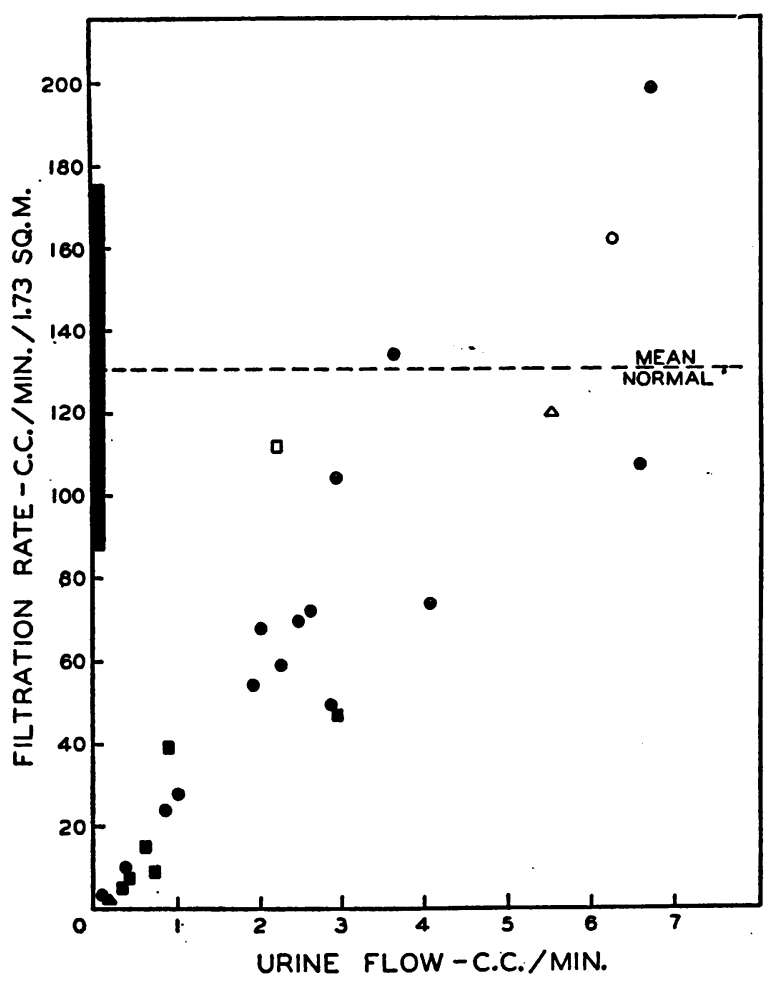

Fig. 7. Correlation Between Rate of Filtration and Urine Flow in All Cases in Which Mannitol was USED to MEASURE the FiLtration RATE

It is to be emphasized that this high degree of correlation is a consequence of the osmotic diuretic action of the mannitol. See text for details.

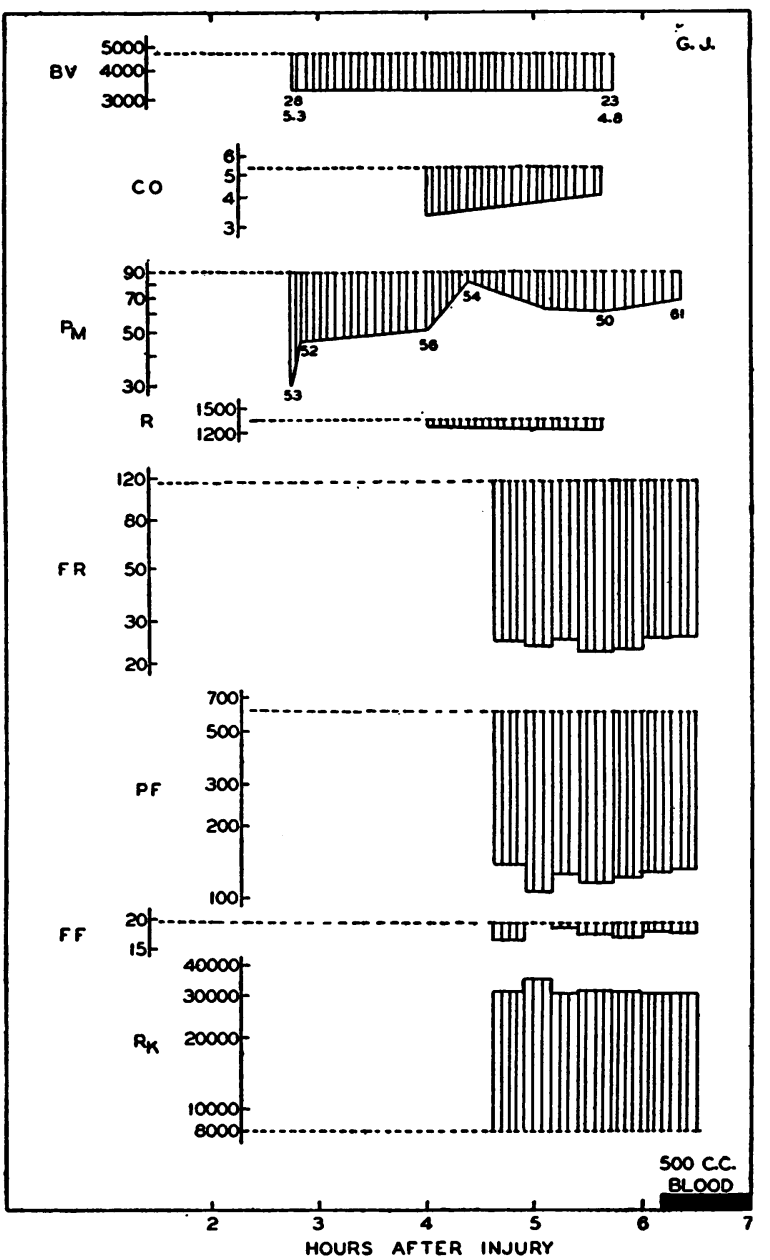

Fig. 8. G. J., 65-Year-Old Male. Compound FractURES OF Extremities and Ruptured SpleEN. Usual Signs of Shock Present

Normal averages are used as base-lines since no control study was done. All ordinates are plotted logarithmically. $B V$, total blood volume in cc.; $C O$, cardiac output in liters per minute; $P_{M}$, mean arterial blood pressure in $\mathrm{mm}$. of mercury; $R$, total peripheral resistance in dynes $\mathrm{cm}^{-6}$ seconds (absolute units); $F R$, rate of glomerular filtration in cc. per minute; $P F$, effective renal plasma flow in cc. per minute; $F F$, filtration fraction in per cent; $R_{K}$, effective renal vascular resistance in dynes $\mathrm{cm} .{ }^{-b}$ seconds. The small figures below the blood volume represent hematocrit and plasma protein values, while those beneath blood pressure indicate pulse rate.

Blood pressure rose from initial low level of $30 \mathrm{~mm}$. of mercury and ranged from 82 to 62 during the renal study. The stability, at a depressed level, of both general and renal circulations is well shown in this case. The urine flow averaged only $0.05 \mathrm{cc}$. per minute during the first hour, but increased to about $1.0 \mathrm{cc}$. per minute after mannitol was given for the renal study (osmotic diuresis). Blood transfusion was begun just before the study was terminated to permit surgical treatment of the fractures. The bradycardia was probably related to bundle branch block discovered in an electrocardiogram. 


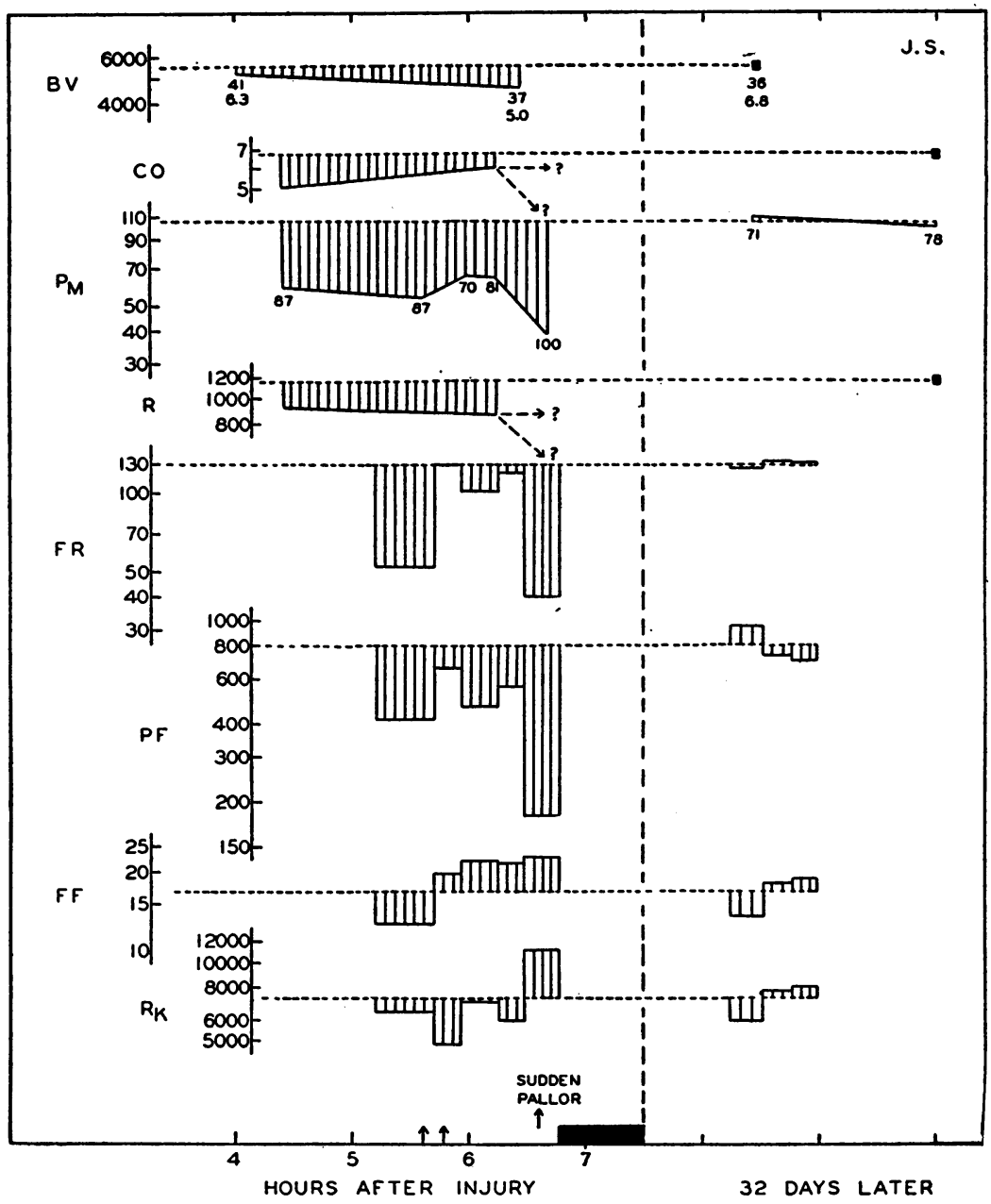

Fig. 9. J. S., 45-Year-Old Male. Multiple Compound and Comminuted Fractures of Both Bones of Right Lower Leg, and Acute Alcoholism

Units of measurement as in Figure 8. Base-lines indicate values obtained in a repeated study made 32 days after injury.

Other than a moderate decrease in blood pressure, there was no evidence of shock until about 2 hours after the beginning of the study, at which time (just before transfer to the operating room), the skin became pale and clammy, the blood pressure dropped sharply, and the renal blood flow and filtration rate decreased almost proportionately. Renal clearances were not greatly depressed prior to the fall in blood pressure. Adrenal cortex extract (Upjohn), $100 \mathrm{cc}$. intravenously, given at the times indicated by the arrows, had no definite effect on general hemodynamics and the apparent rise in clearances following the injections is not different from that observed spontaneously in other cases in which no cortical extract was given (see Figure 10). The variability of the clearances indicates a vasomotor instability which contrasts with the steady state seen in Figure 8. Whether the sudden collapse was due primarily to arteriolar dilatation, or to failure of venous return and decreased cardiac output (venous pooling), cannot be answered since cardiac output was not measured at the time. Alcoholism is believed responsible for most of the initial hypotension (decreased peripheral resistance). Note the progressive hemodilution. The solid block on the time scale at the end of original study indicates transfusion of $500 \mathrm{cc}$. of whole blood. 
counted for by the degree of systemic blood pressure reduction. Most of the patients had hemodilution, which decreases the physical viscosity and the colloid osmotic pressure of the blood. Reductions in each would tend to result in a greater filtration for any given level of blood pressure than was observed. It is probable, therefore, that there was an actual increase in the afferent arteriolar resistance in most cases. The variation found was considerable, suggesting that the several factors varied in their relative importance. For example, filtration rates between 10 and $20 \mathrm{cc}$. per minute were associated with mean arterial pressures ranging from 50 to $100 \mathrm{~mm}$. mercury. Conversely, a mean arterial pressure of $70 \mathrm{~mm}$. mercury produced a rate of filtration of only $3 \mathrm{cc}$. per minute in one case and $120 \mathrm{cc}$. per minute in another. ${ }^{7}$

3. Renal blood flow as related to arterial blood pressure; renal resistance. The outstanding feature in Figure 3 is the striking reduction in effective renal blood flow observed in the shock syndrome. The diagonal lines originating from zero define various levels of renal vascular resistance, and were computed directly from the equation

$$
R_{K}=\frac{P_{m} \times 1332}{\text { R.B.F. per second }}
$$

If the flow of blood through the kidneys decreased in proportion to the reduction in blood

\footnotetext{
${ }^{7}$ Quantitative evaluation of the factors involved in glomerular dynamics is difficult in normal subjects $(7,11)$, but becomes more so in an abnormal state like shock. Decrease in the glomerular capillary permeability is unlikely. Furthermore, it is probable that pressure in Bowman's capsule opposing filtration is not increased, but actually may be decreased. Thus, a low filtration rate associated with a fairly high arterial pressure can only mean marked increase in frictional resistance in the afferent vessels.
}

The results in Case $M$. S. were unusual in that the relatively high filtration rate of $39 \mathrm{cc}$. per minute was observed when the mean arterial pressure was at the very low level of $38 \mathrm{~mm}$. mercury. Since the plasma protein and hematocrit were reduced to 4.4 grams and 22 per cent, respectively, it is believed that the factors of viscosity and osmotic pressure reduction played a large part, although afferent vasodilatation may have been present in addition. The filtration fraction was only 7.8 per cent, a value which would ordinarily imply efferent dilatation (11). In reality, this case is too complex to be so simply explained, and serves to illustrate the difficulties of quantitating glomerular dynamics under highly abnormal circumstances. pressure, the regression of $R_{K}$ would occur within the normal resistance range of 4000 to 10,000 absolute units. That such is not the case, however, is evident from the fact that most of the values representing patients in shock are found in zones of increased resistance. Hence, it may be stated that the reduction in renal blood flow was greater than the corresponding fall in blood pressure because of increased resistance in the kidneys. Since the hematocrit was reduced in most instances, a circumstance which, by itself, would tend to decrease resistance, it follows that a considerable degree of renal vasoconstriction must have been present in most of the cases.

4. Renal blood flow and cardiac output; renal fraction. The relationship between cardiac output (total systemic blood flow) and the renal blood flow is shown in Figure 4. In this chart, the diagonal lines indicate increasing values of the effective renal fraction, calculated from the ratio

$$
\text { renal fraction }=\frac{\text { R.B.F. }}{\text { C.O. }}
$$

In only one case where shock was present (J. D.), was the renal fraction greater than the average normal of about 19 per cent. The reduction in effective renal blood flow was greater than the decrease in cardiac output in the majority of shock cases, hence the renal fraction was decreased, indicating that renal vasoconstriction shunted blood away from the functional tissue of the kidneys, presumably to other parts of the body.

5. Renal blood flow as related to blood volume. $A$ priori, a correlation between renal blood flow and the circulating blood volume would be expected on the basis of the oligemia theory of shock. Figure 5 was prepared with this point in mind. Although there is less correlation between decreasing blood volume and decreasing renal blood flow than was seen between blood pressure and cardiac output and the renal blood flow, it will be noted that most of the values representing patients in shock fall below the normal ranges of both blood volume and renal blood flow.

6. Renal blood flow and $p H$ of the blood. The development of uncompensated acidosis during shock suggests a possible relationship to renal 
function. Although Figure 6 shows some correlation between decrease of blood $\mathrm{pH}$ and reduction of renal blood flow, there are some important exceptions to the general trend, e.g., marked reduction in renal blood flow in the presence of normal blood $\mathrm{pH}$. Moreover, in several cases during treatment, the renal blood flow increased while the blood $\mathrm{pH}$ continued to fall (see J. V., M. Mc., and A. H. in Table I). It has been observed that the renal circulation is apparently reduced promptly following injury or hemorrhage, whereas organic acid accumulation depends upon the duration as well as the degree of the circulatory failure (12).

7. Urine flow in shock. Oliguria was observed in nearly all of the shocked patients in whom the urine flow was measured. In some of the most severe cases, complete anuria occurred, and not until the general circulation had improved as a result of treatment did urine flow resume. It is probable that anuria in shock actually indicates almost complete cessation of renal circulation, since the lowest measurable blood flow values were only 5 to 10 per cent of normal, under conditions where corresponding urine flows were still measurable.

The great difference in molecular weight between inulin and mannitol $(5000: 181)$ and the fact that the urinary concentrations were very different (about 5 to 10 times greater in the case of mannitol, in our study) accounts for the fact that the use of mannitol was accompanied by larger urine flows. Thus, most of the values for urine flow shown in Table I are considerably higher than would have been observed if mannitol had not been given. This is clearly shown in Table III. Where mannitol was used, the $\mathrm{U} / \mathrm{P}$ ratio ranged from 9 to 53 , with a mean of 27. With inulin, the range was 19 to 243 , averaging 84 . With both inulin and mannitol, the $U / P$ ratio was lowest when the filtration rate was less than $20 \mathrm{cc}$. per minute (averaging 20 for mannitol and 36 for inulin), suggesting some derangement of the concentrating function in the most severe cases. This is in accord with the observation that the specific gravity of the urine in shock tends to become fixed at about 1.013 (13), and with our own observations in a few cases, that the urine in severe shock tends to become isotonic with plasma, in spite of marked oliguria. It is interesting to note that in no case was the reabsorption of water less than 89 per cent of the quantity filtered, and in most cases, even in the presence of mannitol, more than 93 per cent was reabsorbed.

TABLE III

Showing the osmotic diuretic effect of mannitol Includes all periods from all cases.

\begin{tabular}{l|c|c|c|c}
\hline \hline & \multicolumn{2}{|c|}{ Mannitol } & \multicolumn{2}{|c}{ Inulin } \\
$\begin{array}{c}\text { Range of fil- } \\
\text { tration rate }\end{array}$ & $\begin{array}{c}\text { Number of } \\
\text { periods } \\
\text { averaged }\end{array}$ & Urine flow & $\begin{array}{c}\text { Number of } \\
\text { periods } \\
\text { averaged }\end{array}$ & Urine flow \\
\cline { 2 - 5 } cc. per minute & & $c c$. per minute & & cc. per minute \\
1 to 20 & 20 & 0.4 & 6 & 0.3 \\
21 to 40 & 9 & 1.0 & 5 & 0.6 \\
41 to 60 & 6 & 2.3 & 9 & 0.5 \\
61 to 80 & 13 & 2.5 & 7 & 1.7 \\
81 to 100 & 7 & 3.5 & 5 & 1.5 \\
101 to 120 & 8 & 3.5 & 8 & 1.5 \\
120 and up & 15 & 4.7 & & \\
\hline
\end{tabular}

8. Correlation of mannitol clearance and urine flow. The observation that the mannitol U/P ratio was relatively fixed over a wide range of filtration rates indicated a close correlation between mannitol clearance and urine flow, as illustrated in Figure 7. This suggests $(a)$ that the rate of urine flow in shock depends chiefly upon, and is quite closely regulated by the rate of filtration, and/or (b) that the plasma concentrations of mannitol happened to be high enough and sufficiently uniform to impose upon the filtrate an increase in osmotic pressure, large enough to limit reabsorption of water to the point where the final urinary concentration of mannitol was always about 4 or 5 grams per cent. Since the primacy of the neurohypophysis in the regulation of facultative tubular water reabsorption seems so well established, the first mentioned possibility is believed untenable, except in a gross way. Hence, the correlation in Figure 7 may be considered what one might call an "osmotic accident." Furthermore, no close linear relationship between filtration rate and urine flow has been observed in the absence of mannitol, although, in general, greatly reduced rates of urine flow were associated with low filtration rates.

9. Influence of etiological factors upon renal clearances. No consistent differences have been found in the renal plasma clearances in patients 
with skeletal trauma compared to those with hemorrhage. The tendency toward high filtration fractions in the head injury group has already been mentioned. That shock due to burns results in a distinctive renal clearance pattern is suggested by the data on the 2 patients shown in Table $I$. The filtration rate was disproportionately high in R. G. and probably also in J. R., yielding a high filtration fraction. A third case of burns recently studied showed an even more unusual filtration fraction of 41 per cent, with clearances of inulin and p-aminohippurate of $66 \mathrm{cc}$. and $159 \mathrm{cc}$. per minute per 1.73 square meters of body surface, respectively, measured when the blood volume was reduced to 1700 cc. per square meter of body surface, and the cardiac output to 1.83 liters per minute per square meter. The arterial mean pressure was maintained at the almost normal value of $75 \mathrm{~mm}$. mercury (high peripheral resistance). These data were obtained prior to plasma therapy, suggesting that the fundamental pattern in the other 2 cases had probably not been greatly modified by the plasma administered.

10. Influence of alcoholism on clearances in shock. Because acute alcoholism of moderate or severe degree was present as a complication of trauma or hemorrhage in a substantial number of the patients, an attempt has been made to evaluate its influence. In alcoholics whose loss of blood volume was slight or moderate, blood pressure has been found to be significantly lower than in non-alcoholics having comparable blood loss and cardiac output reduction; i.e., peripheral resistance was usually decreased (12). That there was a tendency for the kidney to participate in this relative vasodilatation is indicated by the observation that $(a)$ the filtration fraction tended to be low (Table II), and (b) some alcoholics had renal blood flows considerably greater than most non-alcoholics with similar blood pressures. The data are inconclusive, however, because of an inadequate number of cases and the multiplicity of factors involved; hence only a general impression can be recorded.

11. Influence of blood or plasma transfusion. Transfusion of relatively large quantities of whole blood or plasma could affect renal filtration and blood flow $(a)$ indirectly, by increasing the blood pressure, $(b)$ by direct pharmacological action of substances contained in the blood which might alter the caliber of the renal vessels, or (c) by means of both. As with alcoholism, it is not possible to draw definite conclusions regarding the effect of transfusion upon renal hemodynamics. However, the following tendencies have been noted: $(a)$ increase in filtration fraction, suggesting a relative constrictor action in the efferent arterioles, similar to most pressor drugs (see Table II); (b) increase in filtration rate concommitant with rising blood pressure; and (c) progressive fall in plasma flow, after an initial rise. ${ }^{8}$ (See Figures 10, 11, and 12.)

12. Clearances during immediate recovery from shock. Perhaps intimately related to the influence of blood transfusion upon the renal circulation is the observation that in practically all cases adequately studied, the renal circulation failed to return to normal by the time the cardiac output and blood pressure had been completely or nearly restored. (See T. D., J. V., S. R., M. M., P. P., and A. S. in Table I and Figures 10 to 12 .)

Up to the present, we have not studied the renal circulation during the days following injury and emergency treatment. However, of the several delayed deaths in this group, none could be definitely ascribed to renal failure. Practically all of the patients re-studied long after recovery from shock (see Table I and Figures 9,10 , and 11) showed normal filtration rate and renal blood flow.

\footnotetext{
${ }^{8}$ Quite similar results have been reported by Corcoran and Page after blood transfusion in dogs previously subjected to hemorrhage (14). Several explanations of our data may be suggested: (a) The bank blood may have contained variable amounts of vasoconstrictor substances (15); (b) it is possible that in shock there is an overproduction of renin which results in depletion of renin-activator (hypertensinogen), in which case the giving of blood or plasma would make available more activator, and the resulting angiotonin (hypertensin) could then exert a pressor effect generally and in the kidneys (16 to 18); or (c) there might be some autonomous intrarenal mechanism which reacts to rapid increases in blood pressure by constricting the efferent arterioles. In a preliminary study of the effect of blood transfusion ( 250 to $500 \mathrm{cc}$.) upon the renal circulation in normal subjects, Chasis et al. (19) found no change in the clearances or filtration fraction. This tends to weaken the first possibility cited above, although the amounts given may have been too small. Obviously, no definite conclusion is possible at the present time.
} 


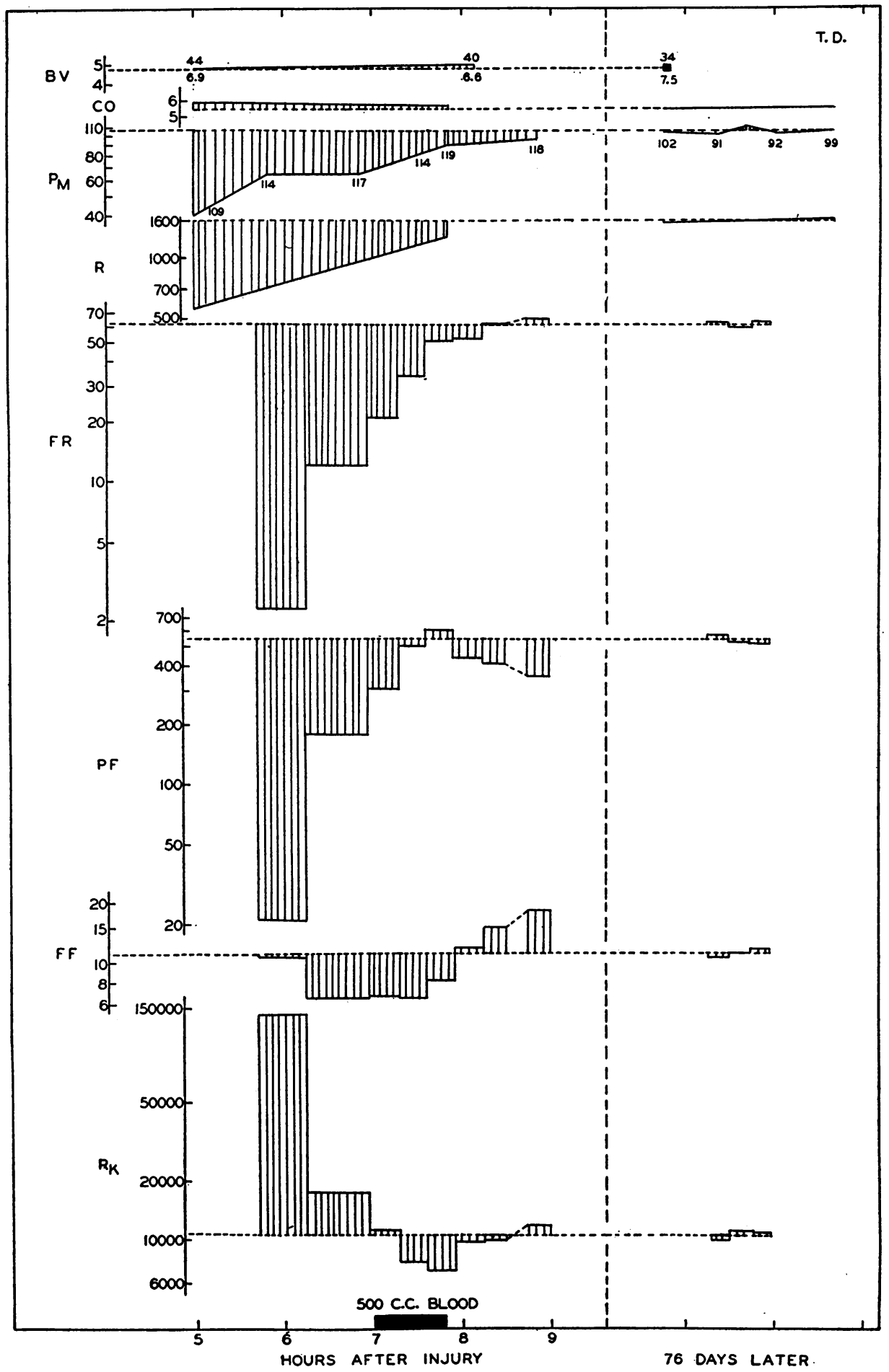

Fig. 10. T. D., 48-Year-Old Male. Fractures of Extremities and Acute Alcoholism

Units of measurement as in Figure 8. Base-lines indicate values obtained in a repeated study 76 days later, at which time the patient was still in casts and in a relatively poor state of nutrition.

Note the striking initial reduction in blood pressure despite normal cardiac output (greatly reduced peripheral resist- 
Details in $\mathbf{5}$ selected cases are illustrated in Figures 8 to 12. Many interesting aspects of the study may be seen in these charts. All explanations are given in the accompanying legends.

\section{DISCUSSION}

Limitations of the clearance methods in shock. In applying a method developed on normal subjects to an unexplored field, such as shock, it is essential to reiterate its limitations and to prove, if possible, its validity. For the historical development of the clearance technics and their general interpretation, reference may be made to the monograph of Smith (20). A detailed discussion of interpretations, particularly as applied to the problem of hypertension but applicable in many respects to the present problem of shock, has been presented by this author (21). Only the most important points can be considered here.

Some of the technical sources of error have been discussed previously, but the fundamental question remains: Does the shock syndrome, with its attendant oligemia, hypotension, anoxia, and acidosis, acutely alter the function of the glomerular membrane and/or the tubular epithelium in such manner that the clearances of mannitol or inulin and of diodrast or p-aminohippurate can no longer be considered identical to the rate of glomerular filtration and plasma flow, respectively? Since direct proof in man is lacking, only some of the possibilities and their consequences as applied to our data can be pointed out.

Decreased permeability of the glomerular membrane as a result of shock is quite unlikely. An increase in permeability would not invalidate the use of inulin or mannitol clearance to measure filtration rate. That the shock syndrome could alter the tubular epithelium to permit some back-diffusion is possible, but it seems unlikely that this could be large enough to alter seriously the general conclusions.

It is quite possible, however, that anoxia could impair the mechanisms by which diodrast and p-aminohippurate are excreted by the tubules, thus reducing the extraction from peritubular blood. A significant decrease in extraction ratio, and consequent error in measurement of total renal plasma flow, would be expected only in the lowest range of clearance figures. For example, hippurate clear- ances over $100 \mathrm{cc}$. per minute might, on the basis of such reasoning, bear about the same relationship to the true renal plasma flow as they do in normal subjects. On the other hand, a clearance of $10 \mathrm{cc}$. per minute might well represent only one-half or one-third of the true plasma flow, corresponding to decrease in extraction ratio to as low as 0.50 or 0.33 .

Important support for this concept has been afforded by the experiments of Phillips and co-workers (22), who have kindly furnished the following summarizing statement:

"Studies of the extraction of para-aminohippuric acid by the explanted kidneys of dogs subjected to hemorrhagic shock and traumatic shock have shown that a constant fraction of about 83 per cent of the hippurate is extracted from the plasma by the kidneys while the renal blood flow is above 10 per cent of normal. At flows lower than this the extraction of hippurate decreases. Thus in a typical case the extraction of hippurate was found to be 37 per cent when the renal blood flow was one per cent of the pre-shock flow. In this instance the renal blood flow calculated from the hippurate clearance, assuming an extraction of 83 per cent, was 0.48 cc. per minute, while it was $1.05 \mathrm{cc}$. per minute when calculated from the hippurate extraction. In general, the use of the factor $\mathbf{0 . 8 3}$ for calculating renal plasma flow from the clearance in dogs leads to only a small absolute error, although this may amount to a large percentage error when the flow is below about 5 per cent of the control value."

On the other hand, the recent report of Corcoran and Page (14) showed a variable decrease in extraction of diodrast in dogs following hemorrhage and transfusion, sometimes when the plasma flow, calculated on the basis of inulin extraction and excretion, was not below normal. Furthermore, these authors found evidence of storage of diodrast during hypotensive periods, the stored material being rapidly washed out during the first few minutes after rapid blood transfusion. The true filtration fraction (extraction ratio for inulin) decreased during bleeding and increased sharply during transfusion, findings which are not unlike those reported in the present communication.

In view of these limitations, caution must be exercised in the interpretation of the results. This may best be appreciated by reference to Figures 1 through 6 , and visualizing the true values for total renal plasma or blood flow in the data having the smallest apparent values as being possibly 2 or 3 times as large as shown. It is important to emphasize, however, that the decrease in kidney circulation resulting from shock remains very large, all possible errors notwithstanding.

Regional vasoconstriction normally follows reduction in blood volume, and the data demon-

ance) and normal blood volume, a circumstance which makes the proper assessment of the degree of shock, if any, quite difficult. Blood pressure, clearances, and urine flow rose spontaneously, and the time lag between them suggests the possibility of prolonged "dead space time" in this case. The effect of the small transfusion was quite dramatic. There was progressive rise in blood pressure and renal clearances during and after the transfusion. The steady increase in filtration fraction was due to a relatively greater increase in filtration rate than plasma flow, the latter actually decreasing after an initial rise. When the patient was re-studied 76 days later, all measurements were normal except for an unexplained low filtration rate, and mild nutritional anemia. 


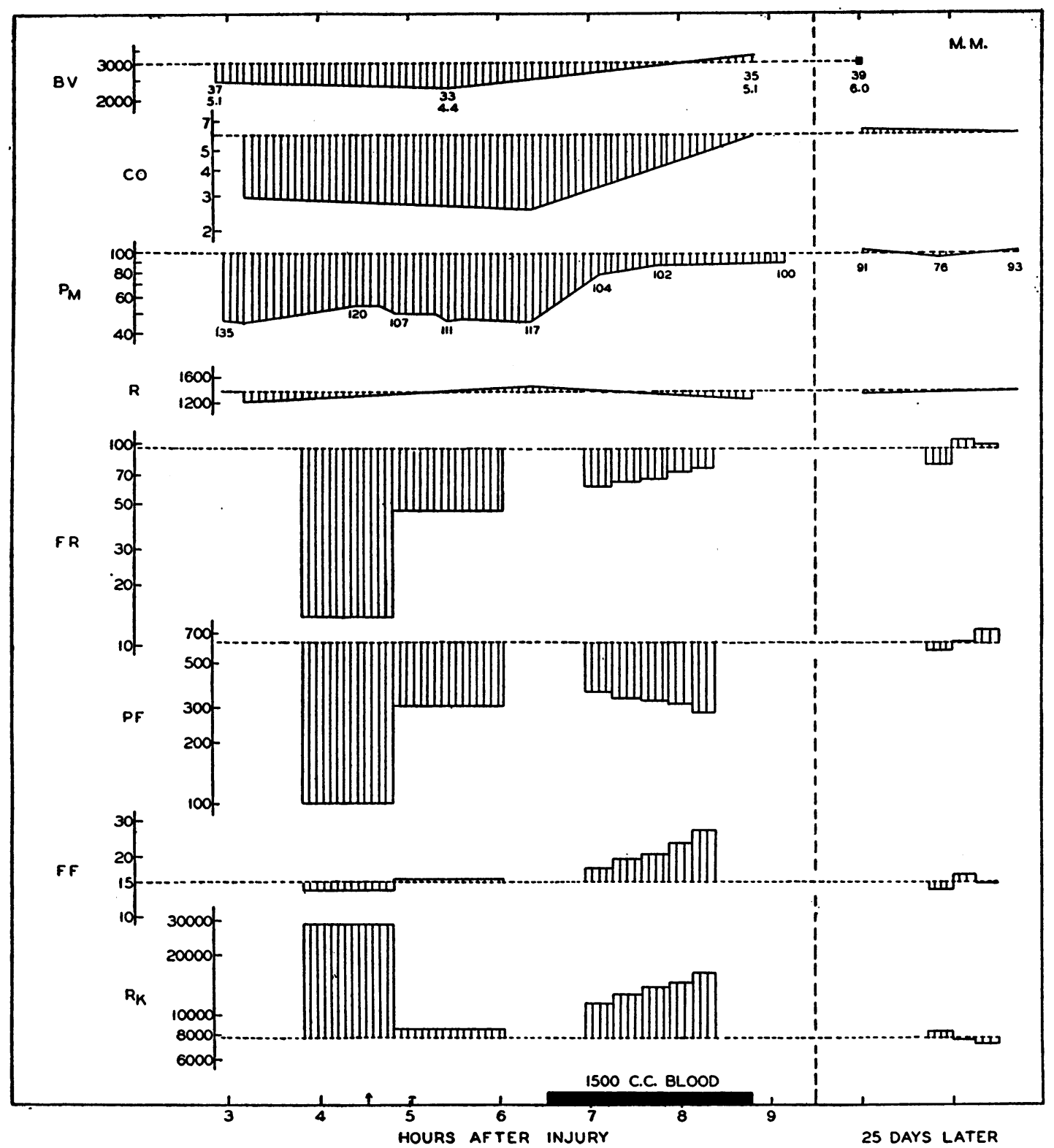

Fig. 11. M. M., 48-Year-Old female. Fractured Pelvis with Retroperitoneal Hemorrhage. Moderately Severe Shock

See Figure 8 for units of measurement. Base-lines represent values obtained 25 days after injury.

Blood pressure and cardiac output were proportionately reduced and remained steady during the 3 hours preceding transfusion of $1500 \mathrm{cc}$. of whole blood. One hundred cc. of adrenal cortex extract intravenously (indicated by arrows on time scale) were without effect on the general circulation. Proportional increases in clearances and urine flow followed the administration of the hormone, not unlike those seen in J. S. (treated with cortical extract) and T. D. (no extract given), suggesting it was a spontaneous occurrence. The parallel increase in cardiac output, blood pressure, filtration rate, and filtration fraction during the transfusion, while the effective plasma flow decreased steadily, illustrates a response similar to that in T. D. This patient had consumed no alcohol. Note that in spite of the return to normal of the cardiac output and mean arterial pressure, the renal blood flow remained distinctly subnormal. Re-study 25 days later yielded normal measurements throughout, except for the blood volume which was considerably below "ideal" normal, and which probably is not a good index of the pre-shock value. 


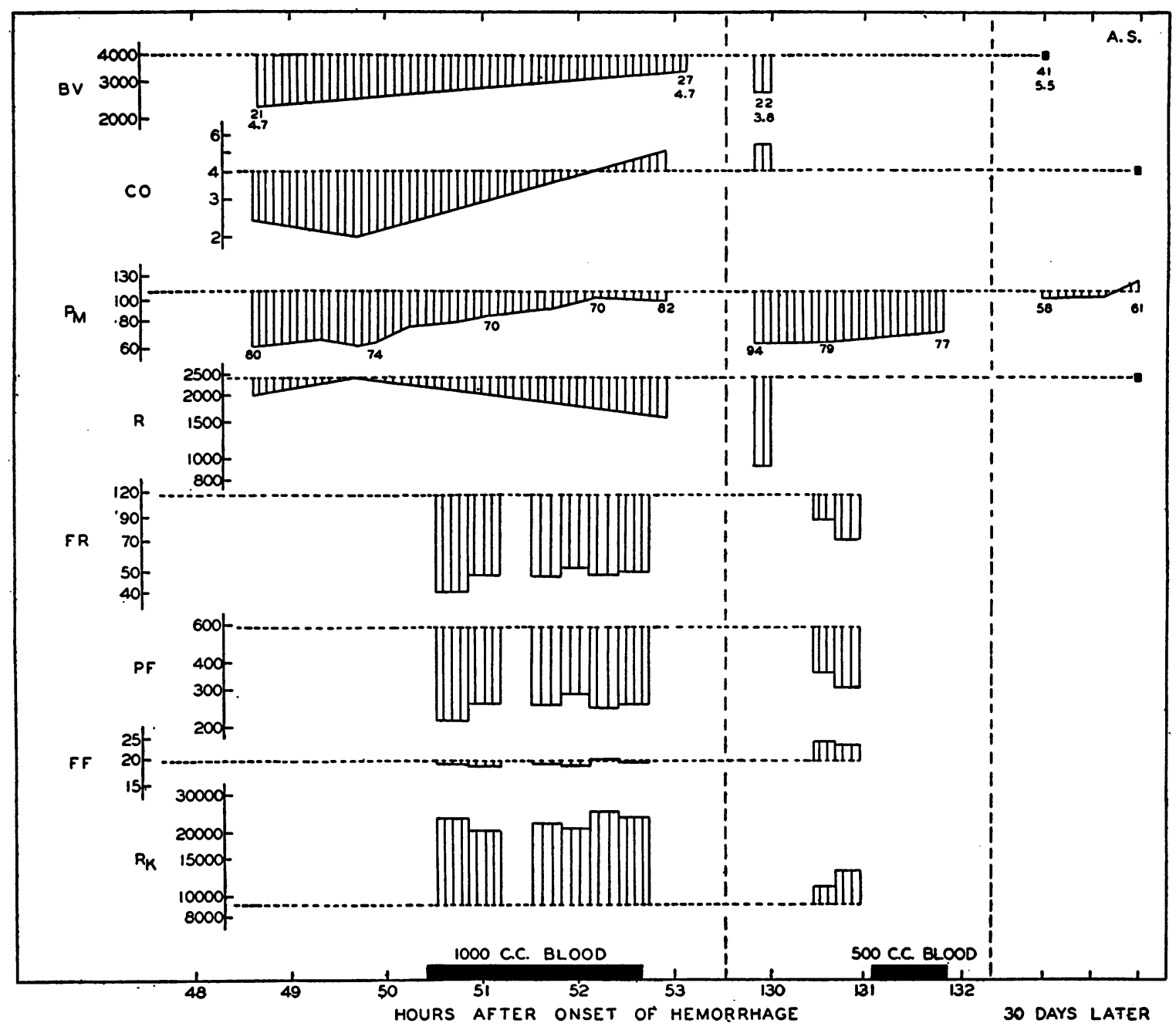

Fig. 12. A. S., female, Aged 60, Vomited Large Amounts of Blood Over a Two-Day Period Because of a Bleeding Peptic Ulcer

She was studied on the day of admission and again three days later. Units of measurement as in Figure 8. Baselines represent control values measured a month later, except in the case of renal clearances, for which average normal values were taken because no renal study could be obtained after recovery.

Cardiac output was reduced relatively more than the blood pressure, indicating high peripheral resistance. She was in moderately severe shock as judged by general appearance and low cardiac output. Response to $1000 \mathrm{cc}$. of blood was much less striking than in previous two cases as far as the renal values and blood pressure were concerned. The color improved remarkably, however, and the cardiac output rose to normal control levels. Filtration fraction remained unchanged, an observation which stands in contrast to the increasing filtration fraction following transfusion in $T$. D. and M. M. Repeated measurements 3 days later revealed interesting changes in the direction of decreased peripheral resistance, as well as decreased renal resistance, with maintenance of normal cardiac output. The renal clearances were distinctly improved at this time. The viscosity and osmotic pressure of the blood were very low (plasma protein, 3.8 grams per $100 \mathrm{cc}$; hematocrit, 22 per cent), probably as a result of large quantities of parenteral fluids given during the preceding 3 days. There can be little doubt that these factors were of considerable importance in the reduction of peripheral and renal resistance, and may have been responsible for the increased filtration fraction at this time. After recovery from gastric resection performed after the second study, the patient was found to be mildly hypertensive. In view of the fairly good clearances observed on the third day, at which time the mean arterial pressure was at the relatively low level of $64 \mathrm{~mm}$. of mercury, it seems probable that the hypertension had not caused significant permanent kidney damage. 
strate that the kidney vessels participate in this constriction. The importance of renal vasoconstriction may be illustrated by Case G. J. (Table I, Figure 8): As a result of trauma, the total blood volume was reduced 30 per cent below the average normal value. The cardiac output decreased from 5.30 liters per minute (our average normal value for a man of $\mathbf{1 . 5 6}$ square meters body surface) to 3.75 liters per minute, a reduction of 1.55 liters per minute, or 29 per cent. At the same time, the renal blood flow was reduced from the average normal of $1000 \mathrm{cc}$. per minute to $160 \mathrm{cc}$. per minute. The net result was that the equivalent of 0.84 liter per minute of blood flow was spared for regions of the body more sensitive to anoxia, such as the brain. By the almost complete exclusion of the kidneys from the circulation by means of vasoconstriction, the blood flow to the rest of the body in this case was actually reduced by only 16 per cent, instead of 29 per cent.

The actual mechanisms involved in the reduction of renal circulation are, of course, not apparent from this investigation. It can be said that the renal resistance is increased in most cases, and that this is due chiefly to increased arteriolar constriction, probably afferent to a large extent, seems to be a reasonable conclusion. Whether the vasoconstriction in the kidneys is on a humoral or neurogenic basis, or both, cannot be answered, but it is clear that acidosis is not the initiating factor. The combination of acidosis and methemoglobinemia, recently shown by Bing (23) to be an effective means of producing a marked renal ischemia, cannot be invoked as an explanation of the renal vasoconstriction in shock, for reasons already stated, and because there was no hemolysis visible in the bloods of our patients.

The interesting observation that the renal circulation was only partially restored by amounts of blood which were adequate to increase the cardiac output to normal could be explained in several ways: (a) If the extraction of p-aminohippurate had been reduced during shock, it is possible that the tubule cells did not recover as promptly as the general circulation. This hypothesis would not account for the persistence of a subnormal filtration rate seen in several patients after transfusion (see especially J. V.,
S. R., and P. P. in Table I, and M. M. and A. S. in Figures 11 and 12). (b) The transfused blood might have contained pressor substances (15). (c) It is possible that the same mechanisms which produced regional vasoconstriction during shock persisted to some extent, possibly because the amount of blood administered was considerably less than that which was lost originally. This is in accord with the observations that a relatively small increase in blood volume often suffices to break the "vicious circle" (12), and implies a two-fold effect of blood transfusion, a blood volume increase and a vaso-pressor effect, which act synergistically to restore the circulation, at least temporarily. In essence, replacement of less blood than was lost appears to change an uncompensated oligemia, or shock, into a compensated one.

Until very recently, there seemed to be no need for special concern regarding recovery of kidney function in the treatment of shock due to trauma (crush injury excluded) or hemorrhage. Because no death had been clearly attributable to renal insufficiency, it was believed that transfusion therapy directed toward restoration of the general circulation was sufficient. However, in a recently studied case of traumatic rupture of the jejunum, renal function did not recover after transfusion, and renal failure with extreme oliguria, azotemia, and acidosis persisted for a week at which time the patient died from peritonitis. Among the possible factors, the duration of circulatory collapse prior to therapy, a considerably longer interval than in most previous cases, seemed the most likely explanation. Because of this experience, it is felt that transfusion must not only be adequate in quantity, but also should be instituted without delay to prevent extensive irreversible damage to the kidneys.

There remains the question of whether the vasoconstriction in shock is uniform throughout the kidney, or whether there is an irregular distribution. In the former, the blood supply to all nephrons would be equally reduced, whereas in the latter, some nephrons, or possibly whole anatomical units of nephrons, would be rendered ischemic. Temporary or permanent tubular damage would be expected only in areas receiving less than a minimal oxygen and blood 
supply over a sufficiently long period. At present, there is little information bearing on this point, but the clinico-pathological study of Penner and Bernheim (24) favors the latter interpretation, since they found the distribution of ischemic cortical necrosis to be irregular in the kidneys of patients dying after prolonged peripheral vascular failure.

\section{SUMMARY AND CONCLUSIONS}

The changes in renal vascular dynamics resulting from peripheral circulatory failure have been investigated by means of the clearance methods in 35 human cases. The study was part of the comprehensive investigation of the circulation in shock carried on at Bellevue Hospital.

The following conclusions may be drawn:

1. The rate of glomerular filtration and effective plasma flow are reduced in practically every case of shock. The reduction is variable but roughly parallels the degree of shock.

2. In most cases, the decrease is greater than can be accounted for solely on the basis of reduced arterial pressure, suggesting active vasoconstriction in the renal vessels. The relationship between the renal blood flow and general circulation has been expressed in terms of two calculated values: The renal fraction, which designates the approximate proportion of total blood flow (cardiac output) which circulates through the kidneys, and the effective renal vascular resistance, which indicates the relation between systemic blood pressure and the renal blood flow. The decrease in renal fraction usually observed reveals that a smaller proportion of the cardiac output flows through the kidneys, indicating that blood is shunted away from the kidneys during shock. The increase in renal resistance indicates that renal vasoconstriction is the mechanism responsible for this redistribution of the circulation.

3. In general, the lowest clearances were associated with lowest blood $\mathrm{pH}$ values, but several lines of evidence indicate that acidosis is not the primary cause of decreased renal circulation. On the contrary, renal ischemia probably augments the acidosis resulting from widespread tissue anoxia.

4. Sources of error and limitations inherent in the clearance methods as applied to the study of shock are discussed. It is concluded that the clearances give a reasonably accurate description of the status of the renal circulation in this condition.

5. Urine flow is uniformly reduced and, in extreme cases, total anuria occurs. In general, the degree of oliguria reflects the reduction in rate of glomerular filtration, which in turn is related to the reduction in renal blood flow.

6. From a limited experience, the impression has been gained that acute alcoholism complicating slight or moderate oligemia tends to result in a relative generalized vasodilatation, which is reflected in the kidney by a lower filtration fraction and a renal blood flow larger than in nonalcoholics with similar levels of blood pressure.

7. The influence of blood or plasma transfusion upon the clearances has been studied. There is a tendency for the filtration fraction to increase, suggesting efferent arteriolar constriction. The filtration rate increases with the rise in arterial pressure, but the renal blood flow tends to remain low or to fall to subnormal values after a temporary increase.

8. In spite of the approximate return to normal of blood pressure and cardiac output, the renal circulation has, in most of the cases which have been adequately studied, failed to improve proportionately during the period of emergency treatment. However, measurements repeated several weeks later revealed a normal filtration rate and effective renal blood flow in all the cases so studied.

9. This investigation confirms the hypothesis that the urinary findings in shock, namely, oliguria or anuria, and loss or impairment of concentrating power, are the result of decreased circulation through the kidneys.

10. Therapy of shock in relation to the kidney is briefly discussed.

The authors gratefully acknowledge the cooperation of the other members of the shock study group, Drs. E. S. Breed, R. L. Riley, and R. P. Noble and Nurses Gertrude Hanafin and Dean Smith. We are indebted to Drs. Homer W. Smith, Dickinson W. Richards, Jr., and M. I. Gregersen for their guidance and helpful criticism.

\section{BIBLIOGRAPHY}

1. Cournand, A., et al., Studies of the circulation in clinical shock. Surgery, 1943, 13, 964. 
2. Finkelstein, N., Aliminosa, L. M., and Smith, H. W., The renal clearances of hippuric acid and pyridone derivatives. Am. J. Physiol., 1941, 133, P276.

3. Smith, H. W., Personal communication.

4. Smith, W. W., Finkelstein, N., and Smith, H. W., Renal excretion of hexitols (sorbitol, mannitol, and dulcitol) and their derivatives (sorbitan, isomannide, and sorbide) and of endogenous creatinine-like chromogen in dog and man. J. Biol. Chem., 1940, 135, 231.

5. Smith, H. W., Goldring, W., and Chasis, H., The measurement of the tubular excretory mass, effective blood flow and filtration rate in the normal human kidney. J. Clin. Invest., 1938, 17, 263.

6. Goldring, W., and Chasis, H., Hypertension and Hypertensive Disease. Commonwealth Press. In press.

7. Lamport, H., Formulae for afferent and efferent arteriolar resistance in the human kidney; an application to the effects of spinal anesthesia. J. Clin. Invest., 1941, 20, 535.

8. Goldring, W., Chasis, H., Ranges, H. A., and Smith, H. W., Relations of effective renal blood flow and glomerular filtration to tubular excretory mass in normal man. J. Clin. Invest., 1940, 19, 739.

9. Hamilton, W. F., Brewer, G., and Brotman, I., Pressure pulse contours in the intact animal. I. Analytical description of a new high frequency hypodermic manometer with illustrative curves of simultaneous arterial and intracardiac pressures. Am. J. Physiol., 1934, 107, 427.

10. Bradley, S. E., and Smith, H. W., The peripheral vascular resistance in normal resting man. In preparation.

11. Smith, H. W., Chasis, H., Goldring, W., and Ranges, H. A., Glomerular dynamics in the normal human kidney. J. Clin. Invest., 1940, 19, 751.
12. Cournand, A., et al., Unpublished data.

13. Fishberg, A. M., Heart Failure. Lea and Febiger, Philadelphia, 1937, p. 581.

14. Corcoran, A. C., and Page, I. H., Effects of hypotension due to hemorrhage and of blood transfusion on renal function in dogs. J. Exper. Med., 1943, 78, 205.

15. Amberson, W. R., Blood substitutes. Biol. Rev., 1937, 12, 48.

16. Dexter, L., Frank, H. A., Haynes, F. W., and Altschule, M. D., Traumatic shock. VI. The effect of hemorrhagic shock on the concentration of renin and hypertensinogen in the plasma in unanesthetized dogs. J. Clin. Invest., 1943, $22,847$.

17. Hamilton, A. S., and Collins, D. A., The homeostatic rôle of a renal humoral mechanism in hemorrhage and shock. Am. J. Physiol., 1942, 136, 275.

18. Sapirstein, L. A., Southard, F. D., Jr., and Ogden, E., Restoration of blood pressure by renin activator after hemorrhage. Proc. Soc. Exper. Biol. and Med., 1942, 50, 320.

19. Chasis, H., Goldring, W., and Whittenberger, J., Personal communication.

20. Smith, H. W., Lectures on the Kidney. Extension Division, University of Kansas, 1943.

21. Smith, H. W., Note on the interpretation of clearance methods in the diseased kidney, J. Clin. Invest., 1941, 20, 631.

22. Phillips, R., Emerson, K. E., Jr., Dole, V. P., Hamilton, P., Archibald, R. M., and Van Slyke, D. D., Personal communications.

23. Bing, R. J., Etiology of renal failure following crush injuries. Proc. Soc. Exper. Biol. and Med., 1943, 53, 29.

24. Penner, A., and Bernheim, A. I., Acute ischemic necrosis of the kidney; a clinicopathologic and experimental study. Arch. Path., 1940, 30, 465. 